\title{
Synthesis, Characterization, and Biological Activity of Some Transition Metal Complexes Derived from Novel Hydrazone Azo Schiff Base Ligand
}

\author{
C. Anitha, ${ }^{1}$ S. Sumathi, ${ }^{1}$ P. Tharmaraj, ${ }^{1}$ and C. D. Sheela ${ }^{2}$ \\ ${ }^{1}$ Department of Chemistry, Thiagarajar College, Madurai 625 009, India \\ ${ }^{2}$ Department of Chemistry, The American College, Madurai 625 002, India
}

Correspondence should be addressed to P. Tharmaraj, sheelatharmaraj@gmail.com

Received 21 November 2011; Accepted 31 December 2011

Academic Editor: Wolfgang Linert

Copyright ( 2011 C. Anitha et al. This is an open access article distributed under the Creative Commons Attribution License, which permits unrestricted use, distribution, and reproduction in any medium, provided the original work is properly cited.

\begin{abstract}
A series of metal(II) complexes ML where $\mathrm{M}=\mathrm{VO}(\mathrm{II}), \mathrm{Co}(\mathrm{II}), \mathrm{Ni}(\mathrm{II}), \mathrm{Cu}(\mathrm{II})$, and $\mathrm{Zn}$ (II) have been synthesized from azo Schiff base ligand ( $\left.\mathrm{N}^{\prime} \mathrm{E}\right)-\mathrm{N}^{\prime}$-(5-((4-chlorophenyl)diazenyl)-2-hydroxybenzylidene)-2-hydroxybenzohydrazide and characterized on the basis of elemental analyses, electronic, IR, and ${ }^{1} \mathrm{H}$ NMR spectra, magnetic susceptibility and also by aid of scanning electron microscopy (SEM), X-ray powder diffraction, fluorescence spectral studies, and molar conductivity measurements. Conductivity measurements reveal that the complexes are nonelectrolytes. Spectroscopy and other analytical studies reveal distorted square planar geometry for copper, square-pyramidal geometry for oxovanadium, and tetrahedral geometry for other complexes. Redox behavior of the copper(II) complex has been studied with cyclic voltammetry, and the biological activities of the ligand and metal complexes have been studied against several microorganisms by the well diffusion method. All synthesized compounds can serve as potential photoactive materials as indicated from their characteristic fluorescence properties. The second harmonic generation (SHG) efficiency of the ligand was measured and found to be higher than that of urea and KDP. The SEM image of the copper(II) complex implies that the size of the particles is $50 \mathrm{~nm}$.
\end{abstract}

\section{Introduction}

Azo Schiff base metal complexes have been studied extensively for years due to the synthetic flexibilities of these Schiff base ligands and their selectivity as well as sensitivity towards the transition metal ions [1]. Among the ligand systems, hydrazide and hydrazones occupy special place because transition metal complexes of these ligands developed due to their chelating capability, structural flexibility, interesting electrical as well as magnetic properties $[2,3]$, and, nowadays, they are extensively being used for their promising applications in the treatment of several diseases and also been used as synthetic and analytical reagents [4], as polymercoating pigment and fluorescent materials [5-9].

Moreover, these ligands exhibit keto-enol tautomerism [10-14] bearing unusual coordination numbers. In the present paper, we report the synthesis and characterization of $\mathrm{VO}(\mathrm{II}), \mathrm{Co}(\mathrm{II}), \mathrm{Ni}(\mathrm{II}), \mathrm{Cu}(\mathrm{II})$, and $\mathrm{Zn}(\mathrm{II})$ complexes of azo Schiff base derived from the condensation of 5-(4chloro-phenylazo)-2-hydroxy benzaldehyde with 2-hydroxybenzohydrazide in a mole ratio of $(1: 1)$, respectively, and, due to the rich chemistry of vanadium metal $[15,16]$, we also aimed to prepare and characterize the vanadyl complex of hydrazone derivative.

\section{Experimental}

The chemicals and solvents were purchased from Aldrich Chemical \& Co., and the solvents were purified by standard methods. Elemental analyses were carried out using a PerkinElmer 2400 II elemental analyzer. Molar conductance of the complexes was measured in DMSO at room temperature using a Systronic Conductivity Bridge 304. Magnetic susceptibility of the complexes was performed on a Sherwood MSB mark1 Gouy balance. Infrared spectral studies were carried out on a Shimadzu FT IR 8000 spectrophotometer using 

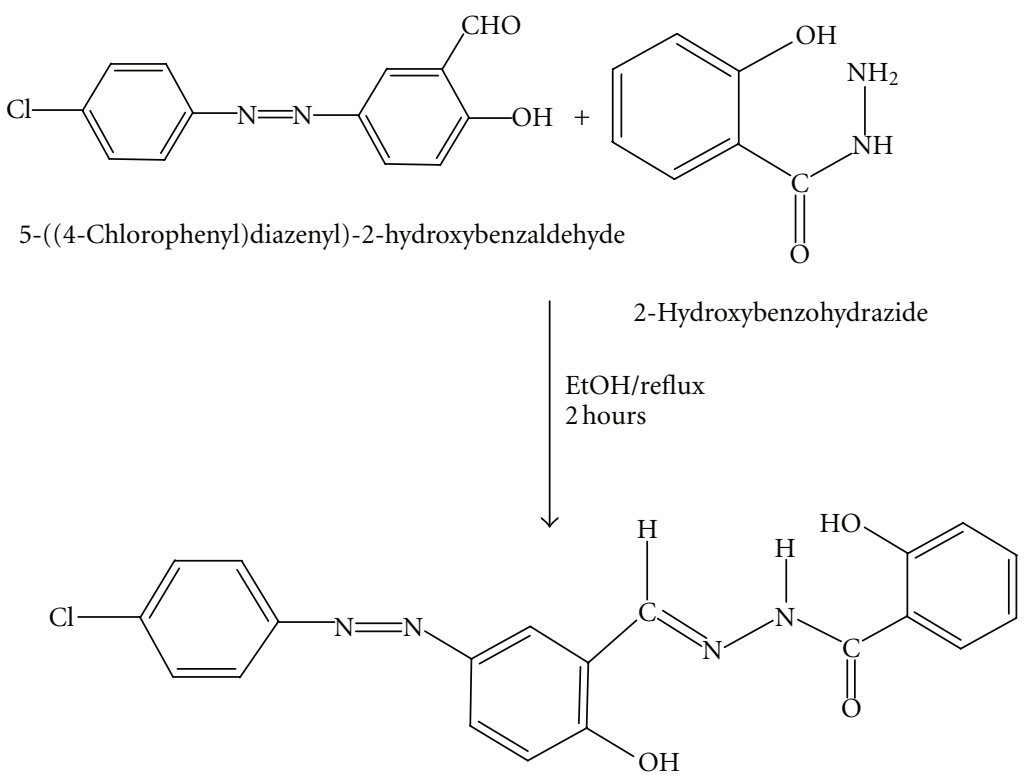

( $\left.N^{\prime} E\right)-N^{\prime}$-(5-((4-Chlorophenyl) diazenyl)-2-hydroxybenzylidene)-

2-Hydroxybenzohydrazide [CDHBHZ]

Figure 1: Synthesis of ligand (CDHBHZ).

$\mathrm{KBr}$ discs. UV-Vis spectra were obtained using a THERMO SPECTRONIC 6 HEXIOS $\alpha$, and fluorescence spectra were determined with an ELICO SL174 spectrofluorometer. NMR spectra were recorded on Bruker DRX-300, $300 \mathrm{MHz}$ NMR spectrometer using TMS as reference. ESR spectra of the $\mathrm{Cu}(\mathrm{II})$ complex were recorded in Varian E112 machine at 300 and $77 \mathrm{~K}$ using tetracyanoethylene (TCNE) as the g marker. Cyclic voltammetric measurement for $\mathrm{Cu}(\mathrm{II})$ complex in DMSO was carried out on an electrochemical analyzer $\mathrm{CH}$ Instruments (USA) using a three-electrode cell containing an $\mathrm{Ag} / \mathrm{AgCl}$ reference electrode, $\mathrm{Pt}$ wire auxiliary electrode, and glassy carbon-working electrode with tetrabutylammonium perchlorate as supporting electrolyte. Electron-ionization (EI) mass spectra were recorded by JEOL-GC Mass Spectrometer MATE-2. The second-harmonic generation (SHG) conversion efficiency of the Schiff base ligand was determined by the modified version of powder technique in IISc, Bangalore. XRD of copper complex was recorded using OCPL/ARD/26. SEM images were recorded in a Hitachi SEM analyzer.

2.1. Preparation of Ligand (CDHBHZ). Azo Schiff base ligand $\left(\mathrm{N}^{\prime} \mathrm{E}\right)-\mathrm{N}^{\prime}-(5-((4-$ chlorophenyl)diazenyl)-2-hydroxybenzylidene)-2 hydroxybenzohydrazide (CDHBHZ) was prepared by adding equimolar amount of 5-((4 chlorophenyl)diazenyl)-2-hydroxybenzaldehyde [17] (1 mmol in $10 \mathrm{~mL}$ of ethanol) to 2-hydroxybenzohydrazide ( $1 \mathrm{mmol}$ in $10 \mathrm{~mL}$ of ethanol). The mixture was refluxed while stirring for 2 hours. The formed solid product was filtered off, washed with ethanol several times followed by recrystallization from ethanol, and finally dried under vacuum (Figure 1).

2.2. Preparation of Metal Complexes. The metal complexes were prepared by adding equimolar amounts of salts of
$\mathrm{VO}$ (II), $\mathrm{Co}(\mathrm{II}), \mathrm{Ni}(\mathrm{II}), \mathrm{Cu}(\mathrm{II})$, and $\mathrm{Zn}$ (II) $(1 \mathrm{mmol}$ in $20 \mathrm{~mL}$ of ethanol) to the azo Schiff base ligand CDHBHZ (1 mmol in $25 \mathrm{~mL}$ of ethanol) in the presence of $1 \mathrm{mmol}$ of $\mathrm{NaOH}$. The mixture was refluxed while stirring for one hour, and the resulting solid complexes were filtered off, washed several times with ethanol, followed by drying under vacuum (Figure 2).

2.3. Antimicrobial Study. The biological activities of synthesized azo Schiff base and their metal complexes have been studied for their antibacterial and antifungal activities by well diffusion method, and the stock solution $(0.001 \mathrm{~mol})$ was prepared by dissolving the compounds in DMSO, and the solutions were serially diluted to find the minimum inhibitory concentration (MIC) values $\left(\mu \mathrm{gmL}^{-1}\right)$. Four bacterial stains (Staphylococcus aureus, Escherichia coli, Pseudomonas aeruginosa, and Bacillus subtilis) were incubated for $24 \mathrm{~h}$ at $37^{\circ} \mathrm{C}$, and fungal stains (Aspergillus niger, Candida albicans, and Rhizoctonia bataticola) were incubated for $48 \mathrm{~h}$ at $37^{\circ} \mathrm{C}$. Standard antibacterial Streptomycin and antifungal drug nystatin were used for comparison under similar conditions. Antimicrobial activity studies were performed in triplicate, and the average was taken as the final reading.

2.4. NLO Study. The second-harmonic generation (SHG) conversion efficiency of the Schiff base was determined by modified version of powder technique developed by Sumathi et al. [18]. The compound was ground into powder and packed between two transparent glass slides. An Nd:YAG laser beam of wavelength $1064 \mathrm{~nm}$ was made to fall normally on the sample cell. The transmitted fundamental wave was absorbed by a $\mathrm{CuSO}_{4}$ solution, which removes the incident $1064 \mathrm{~nm}$ light and Filter BG-38 also removes any residual $1064 \mathrm{~nm}$ light. Interference filter band width is $4 \mathrm{~nm}$ and 

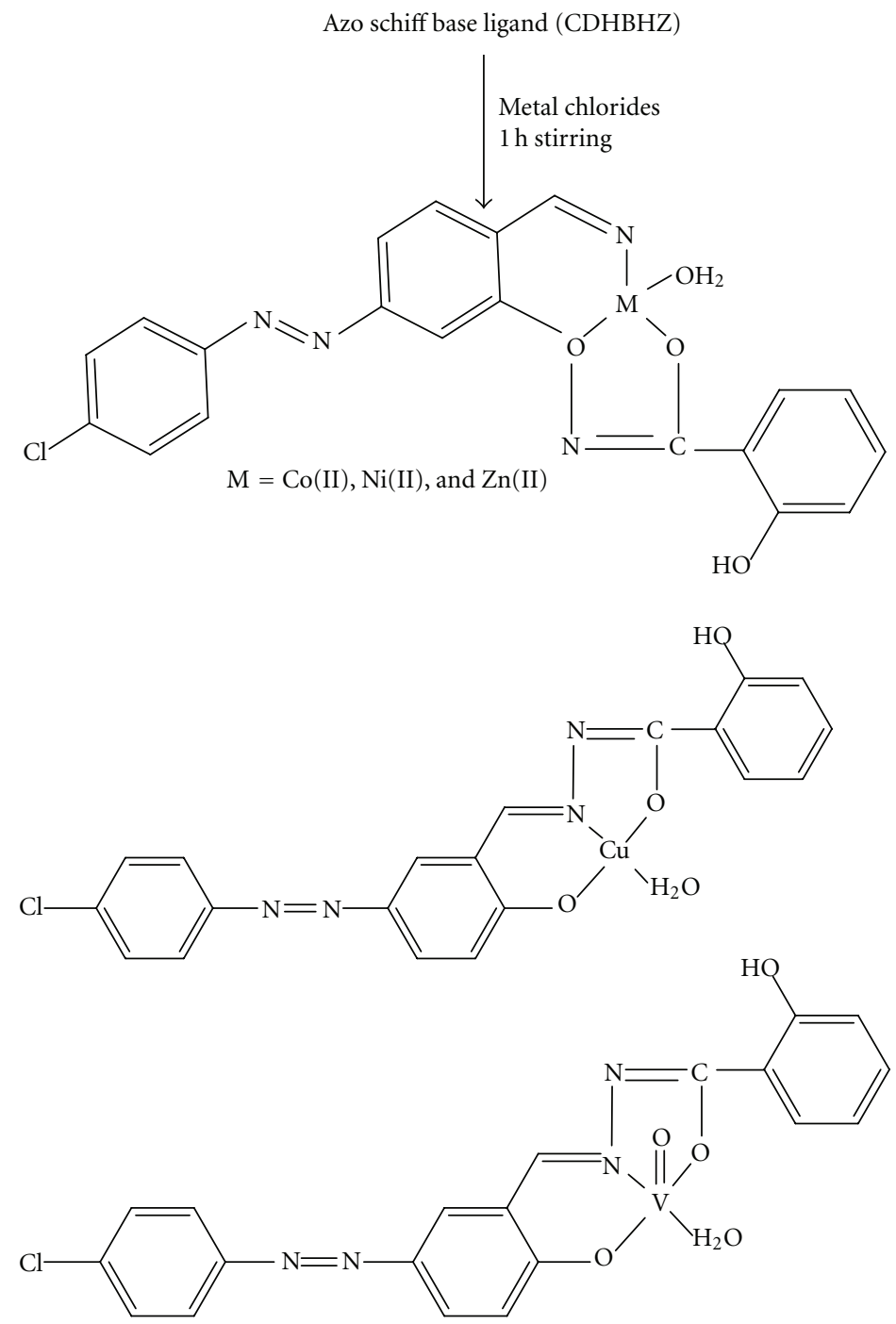

Figure 2: Proposed structure of metal(II) complexes.

for central wavelength of $532 \mathrm{~nm}$. The green light is finally detected by the photomultiplier tube and displayed on the oscilloscope. The second harmonic signal was detected by a photomultiplier tube and displayed on a storage oscilloscope. The efficiency of the sample was compared with microcrystalline powder of KDP and urea. The input energy used in this particular setup is $2.2 \mathrm{~mJ} /$ pulse.

\section{Results and Discussion}

The azo Schiff base ligand was prepared by reacting equimolar amounts of 5-((4-chlorophenyl)diazenyl)-2-hydroxybenzaldehyde with 2-hydroxybenzohydrazide in ethanol medium. The structures of the ligand and the complexes were established from their IR, ${ }^{1} \mathrm{H}-\mathrm{NMR}$ spectra, elemental analyses, and magnetic susceptibility measurements. The complexes are intensely coloured stable solids, and the low molar conductance values of the complexes reveal their nonelectrolytic nature. The results of the elemental analysis (Table 1) of the Schiff base are in good agreement with those calculated for the suggested formula and agree with a 1:1 metal to ligand stoichiometry for all the complexes.

3.1. Infrared Spectra. The structurally significant IR bands for free ligand and its complexes have been reported in Table 2. The free ligand exhibits IR bands at $3207 \mathrm{~cm}^{-1} v(\mathrm{~N}-$ $\mathrm{H}), 1693 \mathrm{~cm}^{-1} v(\mathrm{C}=\mathrm{O})$, and $1620 \mathrm{~cm}^{-1} v(\mathrm{C}=\mathrm{N})$. The bands at 3451 and $2923 \mathrm{~cm}^{-1}$ in the free ligand are attributed to the free $\mathrm{OH}$ stretching of the diazonium moiety and phenolic moiety [19]. In the complexes, the band due to phenolic $\mathrm{OH}$ vibrations remained unaltered, suggesting the noninvolvement of the phenolic proton in the complex formation, whereas the band at $3451 \mathrm{~cm}^{-1}$ due to diazonium moiety disappeared, indicating deprotonation of the $\mathrm{OH}$ group and subsequent coordination of the oxygen to the metal ion. This fact was further confirmed by the ${ }^{1} \mathrm{H}$ NMR study, and this is not appropriate for all the reported complexes as most of the metal ions are paramagnetic. The band at $1620 \mathrm{~cm}^{-1}$ due to the azomethine group of the ligand [20] underwent a shift to lower frequency (by $1610-1589 \mathrm{~cm}^{-1}$ ) 
TABLE 1: Physical characterization, analytical and molar conductance data of the ligand (CDHBHZ), and its metal(II) complexes.

\begin{tabular}{|c|c|c|c|c|c|c|c|c|}
\hline \multirow[b]{2}{*}{ Compound } & \multicolumn{8}{|c|}{ Experimental (Calcd.) (\%) } \\
\hline & $\begin{array}{l}\text { Formula weight } \\
\qquad\left(\mathrm{g} \mathrm{mol}^{-1}\right)\end{array}$ & M & $\mathrm{C}$ & $\mathrm{H}$ & $\mathrm{N}$ & Yield \% & m.p. ${ }^{\circ} \mathrm{C}$ & $\begin{array}{c}\Lambda_{M} \\
\left(\mathrm{~S} \mathrm{~cm}^{2} \mathrm{~mol}^{-1}\right)\end{array}$ \\
\hline $\begin{array}{l}{\left[\mathrm{C}_{20} \mathrm{H}_{15} \mathrm{~N}_{4} \mathrm{O}_{3} \mathrm{Cl}\right]} \\
(\mathrm{CDHBHZ})\end{array}$ & 394.82 & - & $60.82(60.84)$ & $3.84(3.83)$ & $14.20(14.19)$ & 92 & 286 & - \\
\hline$\left[\mathrm{VOL} \cdot \mathrm{H}_{2} \mathrm{O}\right]$ & 492.79 & $10.33(10.34)$ & $51.19(51.18)$ & $3.69(3.68)$ & $11.35(11.37)$ & 86 & $>360$ & 10.4 \\
\hline$\left[\mathrm{CoL} \cdot \mathrm{H}_{2} \mathrm{O}\right]$ & 484.78 & $12.18(12.16)$ & $51.99(52.03)$ & $3.73(3.74)$ & $11.59(11.56)$ & 79 & $>360$ & 10.9 \\
\hline$\left[\mathrm{NiL} \cdot \mathrm{H}_{2} \mathrm{O}\right]$ & 484.54 & $12.09(12.11)$ & $52.01(52.05)$ & $3.75(3.74)$ & $11.55(11.56)$ & 90 & $>360$ & 9.5 \\
\hline$\left[\mathrm{CuL} \cdot \mathrm{H}_{2} \mathrm{O}\right]$ & 489.39 & $10.97(12.98)$ & $51.55(51.54)$ & $3.70(3.71)$ & $11.42(11.45)$ & 87 & $>360$ & 8.9 \\
\hline$\left[\mathrm{ZnL} \cdot \mathrm{H}_{2} \mathrm{O}\right]$ & 491.24 & $13.32(13.31)$ & $51.37(51.35)$ & $3.71(3.69)$ & $11.43(11.41)$ & 76 & $>360$ & 10.2 \\
\hline
\end{tabular}

TABLE 2: Selected IR frequencies of CDHBHZ and its metal(II) complexes $\left(\mathrm{cm}^{-1}\right)$.

\begin{tabular}{|c|c|c|c|c|c|c|}
\hline Compound & $\nu(\mathrm{N}-\mathrm{H})$ & $v(\mathrm{CH}=\mathrm{N})$ & $\nu(\mathrm{C}=\mathrm{O})$ & $\nu(\mathrm{N}=\mathrm{C}-\mathrm{O})$ & $v(\mathrm{M}-\mathrm{O})$ & $v(\mathrm{M}-\mathrm{N})$ \\
\hline CDHBHZ & 3207 & 1620 & 1693 & - & - & - \\
\hline$\left[\mathrm{VOL} \cdot \mathrm{H}_{2} \mathrm{O}\right]$ & - & 1602 & - & 1526 & 516,619 & 480 \\
\hline$\left[\mathrm{CoL} \cdot \mathrm{H}_{2} \mathrm{O}\right]$ & - & 1594 & - & 1506 & 526,582 & 426 \\
\hline$\left[\mathrm{NiL} \cdot \mathrm{H}_{2} \mathrm{O}\right]$ & - & 1609 & - & 1517 & 511,580 & 431 \\
\hline$\left[\mathrm{CuL} \cdot \mathrm{H}_{2} \mathrm{O}\right]$ & - & 1610 & - & 1525 & 520,611 & 422 \\
\hline$\left[\mathrm{ZnL} \cdot \mathrm{H}_{2} \mathrm{O}\right]$ & - & 1589 & - & 1511 & 516,584 & 425 \\
\hline
\end{tabular}

after complexation, indicating the coordination of azomethine nitrogen to metal ion which was further confirmed by observation of the shift in the $v(\mathrm{~N}-\mathrm{N})$ stretching frequency from $1006 \mathrm{~cm}^{-1}$ to $1021-1047 \mathrm{~cm}^{-1}$ regions [20]. In all complexes, the disappearance of the band at $3207 \mathrm{~cm}^{-1}$, due to $v(\mathrm{NH})$ and $1693 \mathrm{~cm}^{-1}$, due to $v(\mathrm{C}=\mathrm{O})$, supports the deprotonation of $-\mathrm{NH}$ proton and subsequent coordination of the oxygen of the amide carbonyl to the metal ion via enolization. This suggestion is supported by the appearance of a new band in the range $1506-1526 \mathrm{~cm}^{-1}$, which may be assigned to $v(\mathrm{~N}=\mathrm{C}-\mathrm{O})[21]$. This finding may be due to bonding of the ligand with the metal ions through the enolic deprotonated oxygen. The appearance of the new bands in the ranges $511-526 \mathrm{~cm}^{-1}$ and $422-480 \mathrm{~cm}^{-1}$ was taken as on indication of coordination between the metal ions and the oxygen and nitrogen, respectively [5]. In addition to other bands, the vanadyl complex shows a band at $1017 \mathrm{~cm}^{-1}$ attributed to the $\mathrm{V}=\mathrm{O}$ vibration [22].

3.2. ${ }^{1} H$ NMR Spectra. The ${ }^{1} \mathrm{H}$ NMR spectrum of the ligand showed two peaks for the hydroxyl group (13.1 and $12.5 \mathrm{ppm})$, the NH group (11.5 ppm), and the azomethine group, $\mathrm{H}-\mathrm{C}=\mathrm{N}(8.1 \mathrm{ppm})$. The peaks observed as multiplets $7-7.8 \mathrm{ppm}$ can be assigned to aromatic protons. In the spectrum of the $\mathrm{Zn}$ (II) complex, the signal of - NH disappeared indicating that the ligand coordinated to the metal in its enolic form. The signal characteristic to the phenolic hydroxyl group appeared in the same position indicating that the hydroxyl group did not participate in coordination [23].

3.3. Mass Spectra. The mass spectrum of $\mathrm{H}_{2} \mathrm{~L}$ supported the suggested structure of the ligand, revealing a molecular ion $[\mathrm{M}+2]$ peak at $\mathrm{m} / \mathrm{z}$ at 397 , consistent with the molecular weight of the ligand (See Supplementary Material available online at doi:10.1155/2011/493942), whereas the molecular ion $[\mathrm{M}+2]$ peak for $\mathrm{VO}(\mathrm{II}) \mathrm{Co}(\mathrm{II}), \mathrm{Ni}(\mathrm{II}), \mathrm{Cu}(\mathrm{II})$, and $\mathrm{Zn}(\mathrm{II})$ complexes observed at $\mathrm{m} / \mathrm{z}=495,487,486,491$, and 493 equivalent to its molecular weight confirms the stoichiometric composition of $\left[\mathrm{ML}\left(\mathrm{H}_{2} \mathrm{O}\right)\right]$ type (Figure $\mathrm{S} 3$ ).

3.4. Electronic Spectra and Magnetic Moment. The electronic spectra and magnetic moment of the ligand and its metal(II) complexes are listed in (Table 3 ). The absorption bands at 30,303 and $35,087 \mathrm{~cm}^{-1}$ attributed to benzene $\pi \rightarrow \pi^{*}$ transitions are observed in the spectrum of the free ligand. The band at $38,167 \mathrm{~cm}^{-1}$ is assigned to imino $\pi \rightarrow \pi^{*}$ or $n \rightarrow$ $\pi^{*}$ transition [24]. The UV-Vis spectrum of the vanadyl(II) complex exhibits three d-d bands observed at 782, 610, and $428 \mathrm{~nm}$ assignable to ${ }^{2} \mathrm{~B}_{2} \rightarrow{ }^{2} E,{ }^{2} \mathrm{~B}_{2} \rightarrow{ }^{2} \mathrm{~B}_{1}$, and ${ }^{2} \mathrm{~B}_{2} \rightarrow{ }^{2} \mathrm{~A}_{1}$ transitions which are characteristic of square-pyramidal geometry [25]. The spectra of $\left[\mathrm{CoL} \cdot \mathrm{H}_{2} \mathrm{O}\right]$ and $\left[\mathrm{NiL} \cdot \mathrm{H}_{2} \mathrm{O}\right]$ complexes showed absorption bands at 560 and $644 \mathrm{~nm}$ which could be attributed to the ${ }^{4} \mathrm{~A}_{2}(\mathrm{~F}) \rightarrow{ }^{4} \mathrm{~T}_{1}(\mathrm{P})$ and ${ }^{3} \mathrm{~T}_{1}(\mathrm{~F}) \rightarrow{ }^{3} \mathrm{~T}_{1}(\mathrm{P})$ transitions corresponding to the tetrahedral geometry [26] and confirmed by the measured magnetic moments values, 4.21 and 3.32 B.M., respectively [27]. The $\mathrm{Cu}$ (II) complex exhibits an intense band at $654 \mathrm{~nm}$ assignable to the ${ }^{2} \mathrm{~B}_{1} g \rightarrow{ }^{2} \mathrm{~A}_{1} g$ transition, indicating square planar geometry. Also the magnetic moment of 2.01 BM further supports the geometry [28]. The spectra of all the complexes show an intense band at 310-439 $\mathrm{nm}$, which can be assigned to a charge transfer (CT) transition. In the $\mathrm{Zn}$ (II) complex, a tetrahedral structure is proposed, and the diamagnetic behavior was confirmed.

3.5. ESR Spectra. A powder ESR spectrum of copper(II) complex was recorded at room temperature using (TCNE) as reference, and the spin Hamiltonian parameters of the 
TABLE 3: Electronic spectral data of the complexes.

\begin{tabular}{|c|c|c|c|c|}
\hline Compound & Absorption $(\mathrm{nm})$ & Band assignment & Geometry & Magnetic moment (BM) \\
\hline \multirow{3}{*}{ CDHBHZ } & 262 & INCT & \multirow{3}{*}{ - } & \multirow{3}{*}{ - } \\
\hline & 285 & INCT & & \\
\hline & 330 & INCT & & \\
\hline \multirow{3}{*}[\mathrm{VOL}\cdot\mathrm{H}_{2}\mathrm{O}]{} & 782 & ${ }^{2} \mathrm{~B}_{2} \rightarrow{ }^{2} \mathrm{E}$ & \multirow{3}{*}{ Square pyramidal } & \multirow{3}{*}{1.74} \\
\hline & 610 & ${ }^{2} \mathrm{~B}_{2} \rightarrow{ }^{2} \mathrm{~B}_{1}$ & & \\
\hline & 428 & ${ }^{2} \mathrm{~B}_{2} \rightarrow{ }^{2} \mathrm{~A}_{1}$ & & \\
\hline \multirow{3}{*}[\mathrm{CoL}\cdot\mathrm{H}_{2}\mathrm{O}]{} & 325 & INCT & \multirow{3}{*}{ Tetrahedral } & \multirow{3}{*}{4.21} \\
\hline & 425 & INCT & & \\
\hline & 560 & ${ }^{4} \mathrm{~A}_{2}(\mathrm{~F}) \rightarrow{ }^{4} \mathrm{~T}_{1}(\mathrm{P})$ & & \\
\hline \multirow{3}{*}[\mathrm{NiL}\cdot\mathrm{H}_{2}\mathrm{O}]{} & 310 & INCT & \multirow{3}{*}{ Tetrahedral } & \multirow{3}{*}{3.32} \\
\hline & 364 & INCT & & \\
\hline & 644 & ${ }^{3} \mathrm{~T}_{1}(\mathrm{~F}) \rightarrow{ }^{3} \mathrm{~T}_{1}(\mathrm{P})$ & & \\
\hline \multirow{3}{*}[\mathrm{CuL}\cdot\mathrm{H}_{2}\mathrm{O}]{} & 356 & INCT & \multirow{3}{*}{ Distorted square planar } & \multirow{3}{*}{2.01} \\
\hline & 439 & INCT & & \\
\hline & 654 & ${ }^{2} \mathrm{~B}_{1} g \rightarrow{ }^{2} \mathrm{~A}_{1} g$ & & \\
\hline
\end{tabular}

TABLE 4: ESR spectral parameters of copper(II) complex.

\begin{tabular}{lccccccccccc}
\hline Complex & $g_{\|}$ & $g_{\perp}$ & $g_{\text {iso }}$ & $\alpha^{2}$ & $\beta^{2}$ & $A_{\|} \times 10^{4} \mathrm{~cm}^{-1}$ & $A^{\perp} \times 10^{-4} \mathrm{~cm}^{-1}$ & $A_{\text {iso }} \times 10^{-4} \mathrm{~cm}^{-1}$ & $g_{\|} / A_{\|} \mathrm{cm}$ & $K_{\perp}$ & $\mu$ (B.M.) \\
\hline$\left[\mathrm{CuL} \cdot \mathrm{H}_{2} \mathrm{O}\right]$ & 2.22 & 2.04 & 2.10 & 0.77 & 0.82 & 181 & 76 & 111 & 122 & 0.54 & 2.01 \\
\hline
\end{tabular}

$\mathrm{Cu}$ (II) complex are listed in (Table 4). The spectrum of the complex revealed axial features $\left(\mathrm{g}_{\|}>g_{\perp}>2.0023\right)$ and suggests a $d x^{2}-y^{2}$ ground state orbital, characteristic of distorted square-planar geometry in $\mathrm{Cu}$ (II) complexes [29]. Sheela et al. showed that, for an ionic environment, $g_{\|}$is normally 2.3 or larger, but, for a covalent environment, $g_{\|}$is less than 2.3 [30]. The $g_{\|}$value for the $\mathrm{Cu}(\mathrm{II})$ complex is 2.22, consequently the environment is covalent. The observed $K_{\|}(0.62)>K_{\perp}(0.54)$ demonstrates the significant contribution from out-of-plane $\pi$ bonding in metal-ligand bonding. The evaluated value of 0.77 for the bonding parameter $\alpha^{2}$ also indicates that the $\mathrm{Cu}$ (II) complex has covalent character [31]. The empirical factor $f=\mathrm{g}_{\|} / \mathrm{A}_{\|} \mathrm{cm}^{-1}$ is an index of tetragonal distortion, and its value may vary from 105 to 135 for small to extreme distortions in square planar complexes [32], and it depends on the nature of the coordinated atoms [33]. The $f$ value for the $\mathrm{Cu}(\mathrm{II})$ complex is found to be 122 , indicating significant distortion from planarity (Figure 54 ).

3.6. Antimicrobial Study. The antimicrobial activity results (Table 5) reveal that the $\mathrm{Cu}(\mathrm{II})$ and $\mathrm{Co}(\mathrm{II})$ complex shows fairly good activity against all the tested bacterial strains, and in general the activity order of the synthesized compounds can be represented as $\mathrm{Cu}(\mathrm{II})>\mathrm{Co}(\mathrm{II})>\mathrm{Ni}(\mathrm{II})>\mathrm{Zn}(\mathrm{II})>$ $\mathrm{VO}(\mathrm{II})>\mathrm{L}$. The higher activity of the metal complexes may be owing to the effect of metal ions on the normal cell membrane [34]. Metal chelates bear polar and nonpolar properties together; this makes them suitable for permeation to the cells and tissues. In addition, chelation may enhance or suppress the biochemical potential of bioactive organic species. Further, lipophilicity, which controls the rate of entry of molecules into the cell, is modified by coordination, so the metal complex can become more active than the free ligand. Therefore, the metal complexes show greater antimicrobial activities than the uncoordinated ligand and free metal ion which in fact is in agreement with the literature [35]. These mixed-ligand complexes have an advantage in that the respective bioactivities of the uncoordinated ligands and metal ions are combined which could make them more potent antimicrobial agents.

3.7. Redox Behavior. Cyclic voltammograms of the copper complex was recorded in DMSO solution, with $0.1 \mathrm{~mol} \mathrm{dm}^{-3}$ TBAP as supporting electrolyte, and the results are summarized in (Table 6). It clearly reveals that the redox process of the copper(II) complex at the scan rate $200 \mathrm{mV}$ involves one-step reduction cathodic peak for $\mathrm{Cu}(\mathrm{II}) \rightarrow \mathrm{Cu}(0)$ at $E_{\mathrm{pc}}=[0.7491 \mathrm{~V}]$. In the anodic side, the direct oxidation of $\mathrm{Cu}(\mathrm{II}) \rightarrow \mathrm{Cu}(0)$ is observed with a strong stripping peak at $E_{\mathrm{pa}}=[-0.2652 \mathrm{~V}][36]$. The reversibility of the copper(II)/ copper(0) couple was checked by varying the scan rates with peak potentials. From the table, it is observed that $E_{\mathrm{pc}}$ and $E_{\mathrm{pa}}$ value changes with the scan rate, and $\Delta E_{p}$ values increase with increasing scan rate and is found to be more than $400 \mathrm{mV}$, and the ratio of anodic to cathodic peak currents $\left(\mathrm{I}_{\mathrm{pc}} / \mathrm{I}_{\mathrm{pa}} \approx 1\right)$ corresponds to a simple one electron process. The difference in the value of $E_{\mathrm{pc}}-E_{\mathrm{pa}}$ is $\Delta E_{p}$ which is larger than the value required for a reversible process $(59 \mathrm{mV})$ indicating that, reduction of $\mathrm{Cu}(\mathrm{II})$ at silver electrode is not only diffusion controlled but also by electron transfer kinetics. These observations indicate that the electron transfer process is irreversible (Figure S5). 
TABLE 5: The in vitro antimicrobial activity of ligand, their metal(II) complexes, and free-metal cations evaluated by minimum (MIC inhibitory concentration, $\mu \mathrm{g} / \mathrm{mL})$.

\begin{tabular}{|c|c|c|c|c|c|c|c|}
\hline \multirow{3}{*}{ Compound } & \multicolumn{4}{|c|}{ Antibacterial activity } & \multicolumn{3}{|c|}{ Antifungal activity } \\
\hline & \multicolumn{4}{|c|}{ Metal complexes (free-metal cations) } & \multicolumn{3}{|c|}{ Metal complexes (free-metal cations) } \\
\hline & S. aureus & E. coli & P. aeruginosa & B. subtilis & A. niger & C. albicans & R. bataicola \\
\hline CDHBHZ & 200 & 100 & 350 & 400 & 300 & 200 & 300 \\
\hline$\left[\mathrm{VOL} \cdot \mathrm{H}_{2} \mathrm{O}\right]$ & $75(175)$ & $55(-)$ & $200(300)$ & $150(-)$ & $175(370)$ & $50(275)$ & $200(250)$ \\
\hline$\left[\mathrm{CoL} \cdot \mathrm{H}_{2} \mathrm{O}\right]$ & $10(350)$ & $15(095)$ & $25(500)$ & $20(410)$ & $55(650)$ & $10(-)$ & $75(-)$ \\
\hline$\left[\mathrm{NiL} \cdot \mathrm{H}_{2} \mathrm{O}\right]$ & $30(215)$ & $25(150)$ & $20(550)$ & $80(-)$ & $60(400)$ & $70(350)$ & $35(450)$ \\
\hline$\left[\mathrm{CuL} \cdot \mathrm{H}_{2} \mathrm{O}\right]$ & $10(400)$ & $25(275)$ & $20(705)$ & $15(550)$ & $10(515)$ & $10(500)$ & $30(655)$ \\
\hline$\left[\mathrm{ZnL} \cdot \mathrm{H}_{2} \mathrm{O}\right]$ & $90(205)$ & $45(-)$ & $100(370)$ & $200(-)$ & $50(-)$ & $50(105)$ & $75(305)$ \\
\hline Standard & 5 & 5 & 10 & 5 & 5 & 10 & 5 \\
\hline
\end{tabular}

TABLE 6: Redox potential for the copper(II) complex.

\begin{tabular}{lccccc}
\hline Complex & Scan rate $\left(\mathrm{mV} \mathrm{s}^{-1}\right)$ & $E_{\mathrm{pc}}(\mathrm{V})$ & $E_{\mathrm{pa}}(\mathrm{V})$ & $\Delta E_{\mathrm{p}}(\mathrm{V})$ & $I_{\mathrm{pc}} / I_{\mathrm{pa}}(\mu \mathrm{A})$ \\
\hline & 100 & 0.523 & -0.151 & 0.674 & 1.142 \\
{$\left[\mathrm{CuL} \cdot \mathrm{H}_{2} \mathrm{O}\right]$} & 150 & 0.612 & -0.201 & 0.813 & 1.136 \\
& 200 & 0.749 & -0.224 & 0.973 & 1.160 \\
\hline
\end{tabular}

TABLE 7: Fluorescence characteristic of ligand and its complexes.

\begin{tabular}{lccc}
\hline Compound & Excitation wavelength $\lambda_{\max }(\mathrm{nm})$ & Fluorescence wavelength $\lambda_{\max }(\mathrm{nm})$ & Quantum yield $(\varphi \mathrm{f})$ \\
\hline $\mathrm{CDHBHZ}$ & 331 & 342 & 0.90 \\
{$\left[\mathrm{VOL} \cdot \mathrm{H}_{2} \mathrm{O}\right]$} & 576 & 621 & 0.46 \\
{$\left[\mathrm{CoL} \cdot \mathrm{H}_{2} \mathrm{O}\right]$} & 405 & 456 & 0.86 \\
{$\left[\mathrm{NiL} \cdot \mathrm{H}_{2} \mathrm{O}\right]$} & 614 & 619 & 0.91 \\
{$\left[\mathrm{CuL} \cdot \mathrm{H}_{2} \mathrm{O}\right]$} & 566 & 572 & 0.92 \\
\hline
\end{tabular}

3.8. Fluorescence Study. The photoluminescence properties of the azo Schiff base ligand and their complexes were studied at room temperature. All the complexes exhibit strong fluorescence with moderate quantum yield (Table 7 ) in comparison to the ligand. The excitation spectra of the ligand show a maximum at $331 \mathrm{~nm}$ and show an emission peak at $342 \mathrm{~nm}$. Generally, azo Schiff base systems exhibit fluorescence due to intraligand $\pi-\pi^{*}$ transitions, and the emission is neither MLCT (metal-to-ligand charge transfer) nor LMCT in nature enhancement of fluorescence through complexation is, however, of much interest as it opens up the opportunity for photochemical applications of these complexes [37] (Figure S6).

3.9. NLO Property. Total first hyperpolarizability $\left(\beta_{\text {tot }}\right)$ for azo Schiff base ligand is studied here and shows the better second harmonic efficiency than urea and KDP. $\left(\mathrm{N}^{\prime} \mathrm{E}\right)-\mathrm{N}^{\prime}-$ (5-((4-chlorophenyl)diazenyl)-2-hydroxybenzylidene)-2-hydroxybenzohydrazide show 1.8 times more activity than urea and KDP, respectively. Ligand has donor-acceptor property, and the electron-withdrawing atom of chlorine can prevent the lone pair electron of nitrogen atom in $\mathrm{N}=\mathrm{N}$ group to be delocalized and causes a reduction in second-order nonlinearity [1]. We can conclude that substituent, chloro group play a role in charge transfer through the molecule, and therefore it seems that the substituents require a special attention in designing the azo Schiff base ligand.

3.10. Powder XRD and SEM Studies. Powder XRD patterns of copper(II) complex show the sharp crystalline peaks indicating their crystalline phase. The crystallite size of the complex $d_{\text {XRD }}$ could be estimated from XRD patterns by applying fullwidth half maximum of the characteristic peak to Scherre's equation using the XRD line broadening method [38] which is as follows:

$$
d_{\mathrm{XRD}}=\frac{0.9 \lambda}{\mathrm{FWHM} \cos \theta},
$$

where $\lambda$ is the wavelength used, FWHM is the full width at half maxima, and $\theta$ is the diffraction angle. The XRD shows that $\mathrm{Cu}$ (II) complex has the crystallite size of $60 \mathrm{~nm}$, respectively. It represents the mean size of every nanocrystallite complexes. All the other complexes support similar crystallite size pattern. The $\mathrm{Cu}(\mathrm{II})$ complex has an average crystallite size of $50 \mathrm{~nm}$. Scanning electron micrography is used to evaluate morphology and particle size of the Schiff base metal complex. The SEM pictures of the samples are shown in. From the figure, an ice square-like shape is observed in the complex with the particle size of $50 \mathrm{~nm}$ (Figure S7). 


\section{Conclusion}

The coordination ability of the newly synthesized azo Schiff base has been proved in complexation reaction with $\mathrm{VO}$ (II), $\mathrm{Co}(\mathrm{II}), \mathrm{Ni}(\mathrm{II}), \mathrm{Cu}(\mathrm{II})$, and $\mathrm{Zn}$ (II) ions. IR, UV-vis spectra, and magnetic measurements of the ligand and its metal complexes confirmed the suggested coordination of the ligand through phenolic carbonyl oxygen, oxygen of $\mathrm{OH}$ group, and nitrogen of the azomethine group as tridentate. The process of chelation dominantly affects the biological activity of the complexes that are potent against pathogens. In general, all the synthesized compounds can serve as potential photoactive materials, as indicated from their characteristic fluorescence properties. Based on these facts, it could be proposed that these novel materials can be better accommodated for optical applications.

\section{Acknowledgments}

Authors thank the management of Thiagarajar College, Madurai, and P. Tharmaraj thanks the Defence Research and Development Organization (DRDO), New Delhi for financial support, SAIF, IIT-Bombay and CDRI, (SAIF) Lucknow for providing analytical facilities.

\section{References}

[1] C. Imrie, P. Engelbrecht, C. Loubser, and C. W. McCleland, "Monosubstituted thermotropic ferrocenomesogens: an overview 1976-1999," Applied Organometallic Chemistry, vol. 15, no. 1, pp. 1-15, 2001.

[2] K. S. Abou-Melha and H. Faruk, "Synthesis, spectral and antimicrobial studies of rare earth metal complexes with Schiffbase hydrazone containing quinoline moiety," Journal of Coordination Chemistry, vol. 61, no. 12, pp. 1862-1874, 2008.

[3] A. Walcourt, M. Loyevsky, D. B. Lovejoy, V. R. Gordeuk, and D. R. Richardson, "Novel aroylhydrazone and thiosemicarbazone iron chelators with anti-malarial activity against chloroquineresistant and -sensitive parasites," International Journal of Biochemistry and Cell Biology, vol. 36, no. 3, pp. 401-407, 2004.

[4] P. V. Bernhardt, P. Chin, P. C. Sharpe, J. Y. C. Wang, and D. R. Richardson, "Novel diaroylhydrazine ligands as iron chelators: coordination chemistry and biological activity," Journal of Biological Inorganic Chemistry, vol. 10, no. 7, pp. 761-777, 2005.

[5] K. Mohanan, S. Nirmala Devi, and B. Murukan, "Complexes of copper(II) with 2-(N-salicylideneamino)-3-carboxyethyl4,5,6, 7-tetrahydrobenzo[ b ] thiophene containing different counter anions," Synthesis and Reactivity in Inorganic, MetalOrganic and Nano-Metal Chemistry, vol. 36, no. 6, pp. 441449, 2006.

[6] S. M. Sondhi, M. Dinodia, and A. Kumar, "Synthesis, anti-inflammatory and analgesic activity evaluation of some amidine and hydrazone derivatives," Bioorganic and Medicinal Chemistry, vol. 14, no. 13, pp. 4657-4663, 2006.

[7] L. Savini, L. Chiasserini, V. Travagli et al., "New $\alpha$-(N)-heterocyclichydrazones: evaluation of anticancer, anti-HIV and antimicrobial activity," European Journal of Medicinal Chemistry, vol. 39, no. 2, pp. 113-122, 2004.

[8] M. Bakir and C. Gyles, "Synthesis, characterization and structure of the first rhenium compound of di-2-pyridyl ketone thiophene-2-carboxylic acid hydrazone (dpktah), fac$[\operatorname{Re}(\mathrm{CO}) 3(\mathrm{~N}, \mathrm{~N}-\kappa 2$-dpktah)Cl]," Journal of Molecular Structure, vol. 918, no. 1-3, pp. 138-145, 2009.

[9] M. F. R. Fouda, M. M. Abd-Elzaher, M. M. Shakdofa, F. A. El-Saied, M. I. Ayad, and A. S. El Tabl, "Synthesis and characterization of a hydrazone ligand containing antipyrine and its transition metal complexes," Journal of Coordination Chemistry, vol. 61, no. 12, pp. 1983-1996, 2008.

[10] M. Bakir, I. Hassan, T. Johnson et al., "X-ray crystallographic, electrochemical and spectroscopic properties of 2-pyridinio 2pyridyl ketone phenyl hydrazone chloride hydrate," Journal of Molecular Structure, vol. 688, no. 1-3, pp. 213-222, 2004.

[11] S. M. Emam, F. A. El-Saied, S. A. Abou El-Enein, and H. A. El-Shater, "Cobalt(II), nickel(II), copper(II), zinc(II) and hafnium(IV) complexes of $\mathrm{N}^{\prime}$-(furan-3-ylmethylene)-2-(4methoxyphenylamino)acetohydrazide," Spectrochimica Acta Part A, vol. 72, no. 2, pp. 291-297, 2009.

[12] K. Andjelkovic, G. Jakovljevic, and M. Zlatovic, "Acid-base equilibria of the $\mathrm{Zn}$ (II) and $\mathrm{Fe}$ (III) complexes with condensation products of 2-acetylpyridine and the dihydrazide of oxalic and malonic acid," Journal of the Serbian Chemical Society, vol. 69, pp. 651-660, 2004.

[13] P. V. Bernhardt, P. Chin, P. C. Sharpe, J. Y. C. Wang, and D. R. Richardson, "Novel diaroylhydrazine ligands as iron chelators: coordination chemistry and biological activity," Journal of Biological Inorganic Chemistry, vol. 10, no. 7, pp. 761-777, 2005.

[14] N. Terzioglu and A. Gürsoy, "Synthesis and anticancer evaluation of some new hydrazone derivatives of 2,6-dimethylimidazo[2,1-b][1,3,4] thiadiazole-5-carbohydrazide," European Journal of Medicinal Chemistry, vol. 38, no. 7-8, pp. 781-786, 2003.

[15] S. A. Dikanov, B. D. Liboiron, and C. Orvig, "Two-dimensional (2D) pulsed electron paramagnetic resonance study of $\mathrm{VO} 2+$-triphosphate interactions: evidence for tridentate triphosphate coordination, and relevance to bone uptake and insulin enhancement by vanadium pharmaceuticals," Journal of the American Chemical Society, vol. 124, no. 12, pp. 29692978, 2002.

[16] E. C. E. Rosenthal, H. Cui, and M. Hummert, "A novel oxovanadium $(V)$ complex of 2-(2-butoxyethoxy)ethanolate with high catalytic activities for polymerisation and epoxidation," Inorganic Chemistry Communications, vol. 11, no. 8, pp. 918920, 2008.

[17] B. S. Furniss, A. J. Hannaferd, and V. Rogers, Vogel's Textbook of Practical Organic Chemistry, Longman, Inc., New York, NY, USA, 4th edition, 1981.

[18] S. Sumathi, P. Tharmaraj, C. D. Sheela, and R. Ebenezer, "Synthesis, spectral, bioactivity, and NLO properties of chalcone metal complexes," Journal of Coordination Chemistry, vol. 64, no. 10, pp. 1707-1717, 2011.

[19] R. Gup and B. Kirkan, "Synthesis and spectroscopic studies of copper(II) and nickel(II) complexes containing hydrazonic ligands and heterocyclic coligand," Spectrochimica Acta Part A, vol. 62, no. 4-5, pp. 1188-1195, 2005.

[20] K. Z. Ismail, "Synthesis, spectroscopic, magnetic and biological activity studies of copper(II) complexes of an antipyrine Schiff base," Transition Metal Chemistry, vol. 25, no. 5, pp. 522-528, 2000.

[21] F. Hueso-Ureńa, N. A. Illán-Cabeza, M. N. Moreno-Carretero, and A. L. Peńas-Chamorro, "Ni(II), Cu(II), Zn(II) and Cd(II) complexes with dinegative N,N,O-tridentate uracil-derived hydrazones," Acta Chimica Slovenica, vol. 47, no. 4, pp. 481$488,2000$. 
[22] N. Raman, L. Mitu, A. Sakthivel, and M. S. S. Pandi, "Studies on DNA cleavage and antimicrobial screening of transition metal complexes of 4-aminoantipyrine derivatives of $\mathrm{N}_{2} \mathrm{O}_{2}$ type," Journal of the Iranian Chemical Society, vol. 6, no. 4, pp. 738-748, 2009.

[23] M. R. Maurya, S. Agarwal, C. Bader, and D. Rehder, "Dioxovanadium $(\mathrm{V})$ complexes of $\mathrm{ONO}$ donor ligands derived from pyridoxal and hydrazides: models of vanadate-dependent haloperoxidases," European Journal of Inorganic Chemistry, no. 1, pp. 147-157, 2005.

[24] P. Tharmaraj, D. Kodimunthiri, C. D. Sheela, and C. S. Shanmuga Priya, "Synthesis, spectral characterization, and antimicrobial activity of copper(II), cobalt(II), and nickel(II) complexes of 3-formylchromoniminopropylsilatrane," Journal of Coordination Chemistry, vol. 62, no. 13, pp. 2220-2228, 2009.

[25] M. Issa, A. Azim, M. Khedr, and F. Draz, "Synthesis, characterization, thermal, and antimicrobial studies of binuclear metal complexes of sulfa-guanidine Schiff bases," Journal of Coordination Chemistry, vol. 62, pp. 1859-1870, 2009.

[26] E. Canpolat, A. Yazici, and M. Kaya, "Studies on mononuclear chelates derived from substituted Schiff-base ligands (part 10): synthesis and characterization of a new 4-hydroxysalicylidenp-aminoacetophenoneoxime and its complexes with $\mathrm{Co}(\mathrm{II})$, $\mathrm{Ni}(\mathrm{II}), \mathrm{Cu}(\mathrm{II})$ and $\mathrm{Zn}(\mathrm{II})$," Journal of Coordination Chemistry, vol. 60 , no. 4 , pp. 473-480, 2007.

[27] M. M. Aboaly and M. M. H. Khalil, "Synthesis and spectrosccopic study of $\mathrm{Cu}(\mathrm{II}), \mathrm{Ni}(\mathrm{II})$ and $\mathrm{Co}(\mathrm{II})$ complexes of the ligand Salicylidene-2-aminothiophenol," Spectroscopy Letters, vol. 34, pp. 495-504, 2001.

[28] R. Karvembu and K. Natarajan, "Synthesis and spectral studies of binuclear ruthenium(II) carbonyl complexes containing bis( $\beta$-diketone) and their applications," Polyhedron, vol. 21, no. 2, pp. 219-223, 2002.

[29] A. García-Raso, J. J. Fiol, B. Adrover et al., "Reactivity of copper(II) peptide complexes with bioligands (benzimidazole and creatinine)," Polyhedron, vol. 22, no. 25-26, pp. 3255-3264, 2003.

[30] C. D. Sheela, C. Anitha, P. Tharmaraj, and D. Kodimunthri, "Synthesis, spectral characterization, and antimicrobial studies of metal complexes of the schiff base derived from [4amino-N-guanylbenzene sulfonamide] and salicylaldehyde," Journal of Coordination Chemistry, vol. 63, no. 5, pp. 884-893, 2010.

[31] M. F. R. Fouda, M. M. Abd-Elzaher, M. M. E. Shakdofa, F. A. El Saied, M. I. Ayad, and A. S. El Tabl, "Synthesis and characterization of transition metal complexes of $\mathrm{N}^{\prime}$ [(1,5-dimethyl-3-oxo-2-phenyl-2,3-dihydro-1H-pyrazol-4yl)methylene] thiophene-2-carbohydrazide," Transition Metal Chemistry, vol. 33, no. 2, pp. 219-228, 2008.

[32] S. Chandra and U. Kumar, "Synthesis, spectroscopic, and antimicrobial studies on bivalent nickel and copper complexes of bis(thiosemicrbazone)," Spectrochimica Acta Part A, vol. 61, pp. 219-224, 2005.

[33] K. B. Gudasi, S. A. Patil, R. S. Vadavi, R. V. Shenoy, and M. Nethaji, "Crystal structure of 2-[2-hydroxy-3-methoxyphenyl]-3-[2-hydroxy-3-methoxybenzylamino]-1,2-dihydroquinazolin-4(3H)-one and the synthesis, spectral and thermal investigation of its transition metal complexes," Transition Metal Chemistry, vol. 31, no. 5, pp. 586-592, 2006.

[34] A. K. Sadana, Y. Mirza, K. R. Aneja, and O. Prakash, "Hypervalent iodine mediated synthesis of 1 -aryl/hetryl-1,2,4-triazolo[4,3-a] pyridines and 1-aryl/hetryl 5-methyl-1,2,4-triazolo[4,3-a] quinolines as antibacterial agents," European Journal of Medicinal Chemistry, vol. 38, no. 5, pp. 533-536, 2003.
[35] M. O. Agwara, P. T. Ndifon, N. B. Ndosiri, A. G. Paboudam, D. M. Yufanyi, and A. Mohamadou, "Synthesis, characterisation and antimicrobial activities of cobalt(II), copper(II) and zinc(II) mixed-ligand complexes containing 1,10-phenanthroline and 2,2'-bipyridine," Bulletin of the Chemical Society of Ethiopia, vol. 24, no. 3, pp. 383-389, 2010.

[36] S. H. Rahaman, R. Ghosh, T. H. Lu, and B. K. Ghosh, "Chelating $\mathrm{N}, \mathrm{N}^{\prime}$-(bis(pyridin-2-yl)alkylidene)propane-1,3-diamine pseudohalide copper(II) and cadmium(II) coordination compounds: synthesis, structure and luminescence properties of $[\mathrm{M}(\mathrm{bpap})(\mathrm{X})] \mathrm{ClO} 4$ and $[\mathrm{M}(\mathrm{bpap})(\mathrm{X}) 2][\mathrm{M}=\mathrm{Cu}, \mathrm{Cd}$; $\mathrm{X}=$ N3-, NCS-]," Polyhedron, vol. 24, no. 12, pp. 1525-1532, 2005.

[37] T. Yu, K. Zhang, Y. Zhao et al., "Synthesis, crystal structure and photoluminescent properties of an aromatic bridged Schiff base ligand and its zinc complex," Inorganica Chimica Acta, vol. 361, no. 1, pp. 233-240, 2008.

[38] C. J. Dhanaraj and M. S. Nair, "Synthesis, characterization, and antimicrobial studies of some Schiff-base metal(II) complexes," Journal of Coordination Chemistry, vol. 62, no. 24, pp. 4018-4028, 2009. 


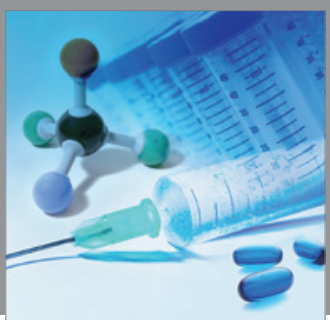

International Journal of

Medicinal Chemistry

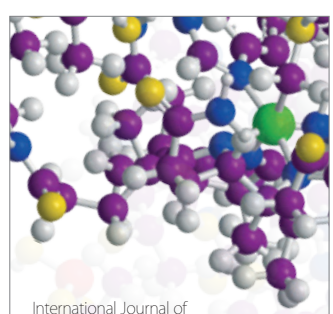

Carbohydrate Chemistry

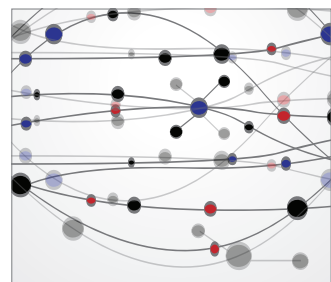

The Scientific World Journal
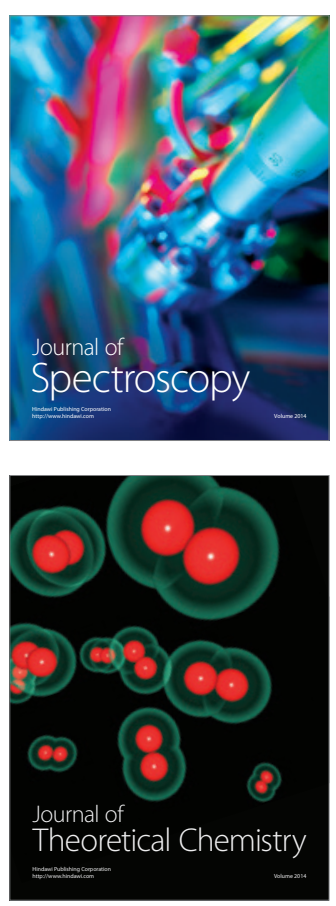
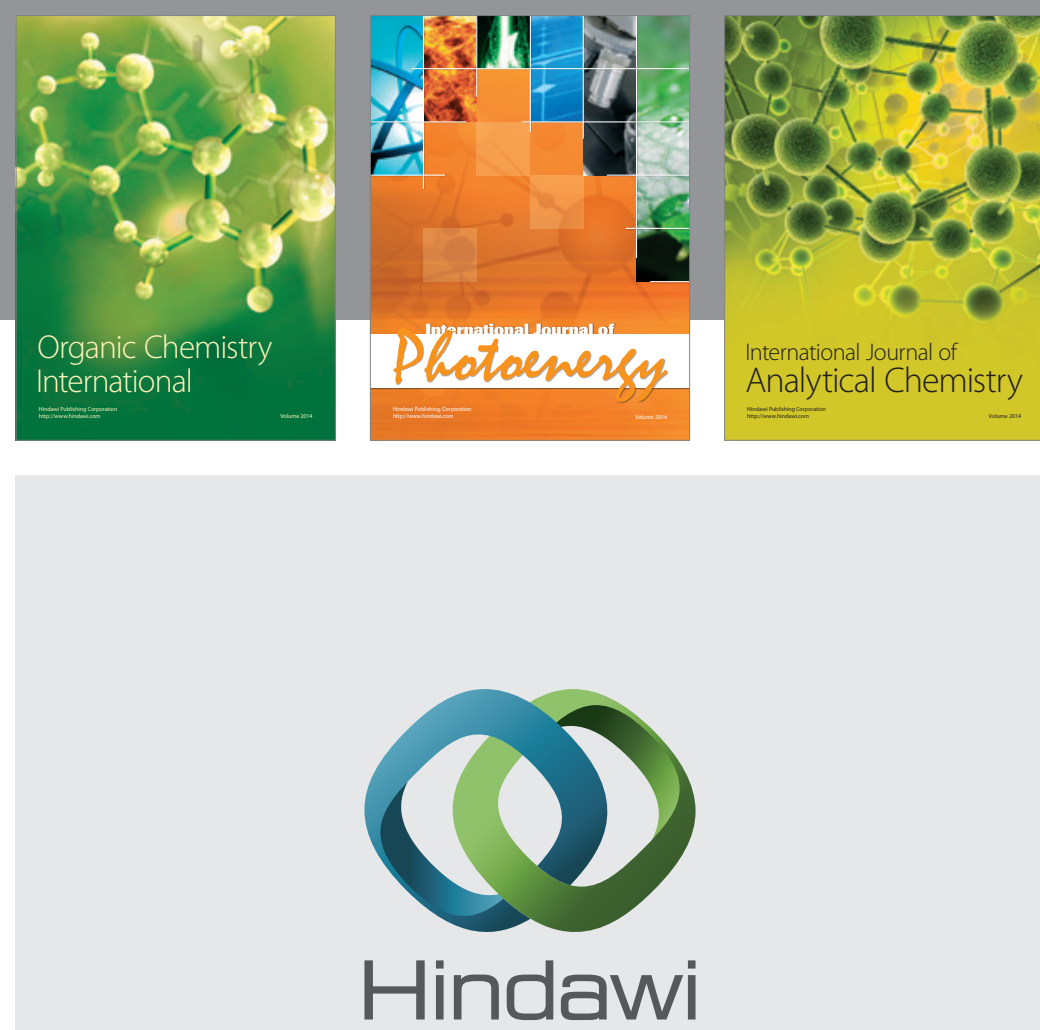

Submit your manuscripts at

http://www.hindawi.com
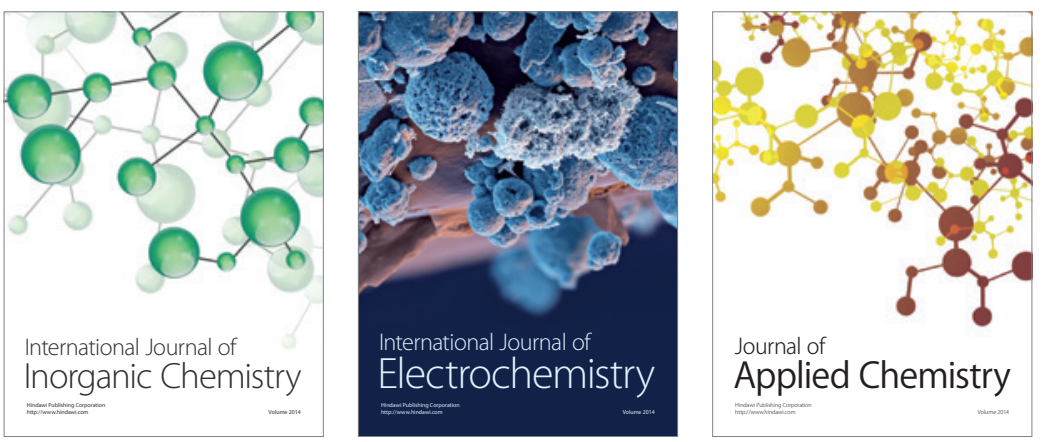

Journal of

Applied Chemistry
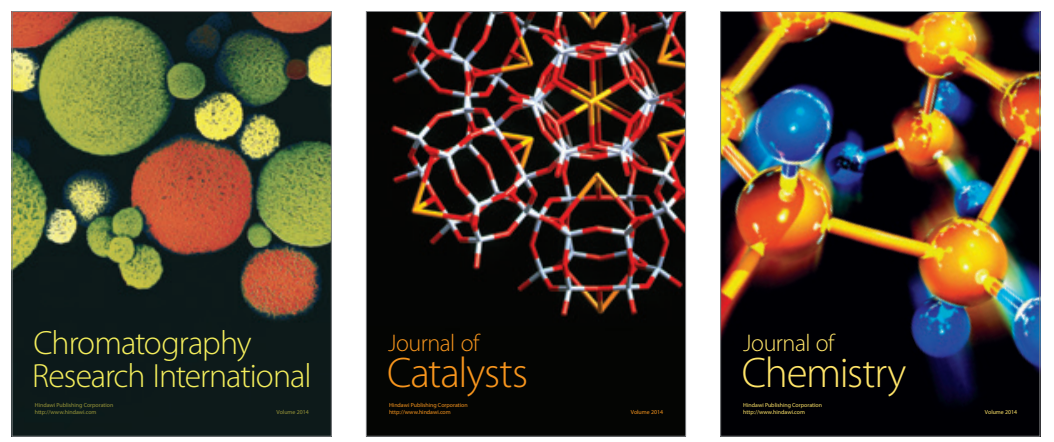
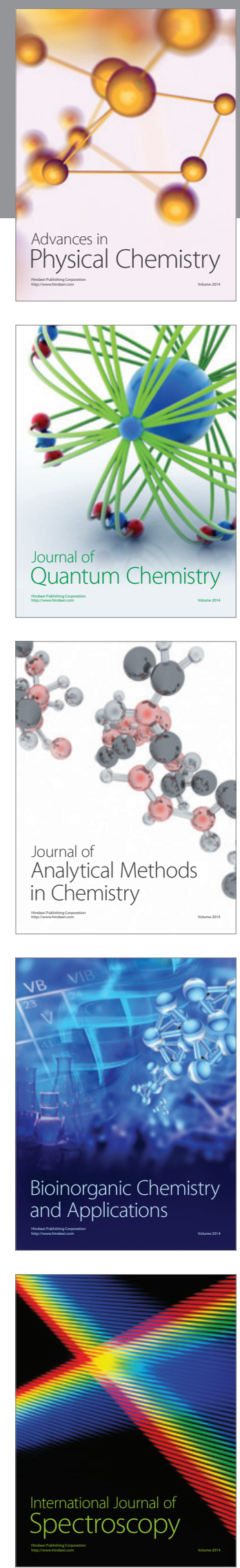